\title{
Exploring the Care Act's potential for anti-discriminatory practice with lesbian, gay, bisexual and trans older people
}

\begin{abstract}
Purpose - The planning and provision of care for older people in the lesbian, gay, bisexual and trans (LGBT) communities is an increasing challenge to traditional welfare systems. This review explores the potential of the newly implemented Care Act 2014 in England for developing an anti-discriminatory approach.

Design/methodology/approach - The review draws on existing research and conceptual literature to identify how key provisions of the new Act can be interpreted in light of current knowledge.

Findings - Overall the provisions of the Care Act lend themselves well to positive interpretation in relation to the needs of older LGBT people and their support networks. A potential tension, however, arises in the locality focus of the legislation that could constrain good practice with geographically dispersed communities. There is also a need to challenge both heteronormative and ageist assumptions that lead to older LGBT people remaining unrecognised.
\end{abstract}

Practical implications - Applied with imagination and commitment, the provisions of the new Act could enable new forms of person-centred care to emerge to support older LGBT people.

Social implications - Social workers are in a key position to influence how the Care Act is interpreted and applied in practice and can act as change agents for a societal move towards older LGBT people having greater choice and control over their wellbeing

Originality/value - This review presents examples of how the provisions of the legislation can be utilised to support positive change for older LGBT people.

Keywords Older People, LGBT, Legislation, Care Act 2014, Social Care, Social Work

Paper type General review 


\section{Introduction}

The legislative framework for the provision of care and support services in England ${ }^{1}$ has recently undergone the most significant reform in more than 60 years. The Care Act 2014 creates a single statute to replace the previous patchwork of poorly aligned adult social care legislation and policy. This should, in principle, make it clearer under which circumstances people can expect to receive care and support. In particular it embeds the personalisation policy agenda (Department of Health, 2007), with a distinct focus on person-centred systems and strengths-based, community-focused approaches. It introduces a minimum national threshold for eligibility, a set of specific outcomefocused criteria that outline when local authorities must provide support.

Social care legislation can be defined as the expression of duties and powers that determine how local authorities must or may act, which is further clarified through the provision of regulations and guidance that connect those duties and powers to principles for practice (Braye \& Preston-Shoot, 2010). Good social work practice is of much greater complexity than simply executing prescribed duties under legislation. Instead it sets boundaries for practice, with considerable discretion within those limits (Brammer, 2010). Specific provisions are open to interpretation and, with new legislation in particular, will often undergo a process of clarification through case law, judicial review or similar processes. As such, the current period of implementation of the Care Act creates optimum conditions for social workers to act, for better or for worse, as 'street-level bureaucrats', individually and collectively shaping the ways in which the provisions of the new Act will be interpreted, understood and applied. 'Street-level bureaucracy' (Lipsky, 1980) refers to the ways communitybased workers enact ambiguous public policies in their day-to-day activities in often constrained circumstances and, arguably, create policy in their interpretations. The degree to which discretion in social work is curtailed by policy, procedures and/or management is contested (Howe, 1991). However, as Evans and Harris (2004) argue, the existence of rules does not preclude discretion, rather they create the conditions for it. The question always remains of which rules apply in which circumstances, as does the necessity for translating policy into practice. This, in turn, can be framed just as readily by negative as positive attitudes.

Working with older people in the lesbian, gay, bisexual and transgender (LGBT) communities is a contemporary challenge for social work to which the response has so far not always been positive, despite professional standards in England that require social workers to be aware of the impact of culture, equality and diversity (Health and Care Professions Council, 2012). Lesbian, gay and bisexual social networks or relationships are often narrowly constructed within social work with adults, with pervasive heterosexism identified from adolescence to old age across health and social care services (Charnley \& Langley, 2007; Cocker \& Hafford-Letchfield, 2010). Charnley and Langley's (2007) review foregrounds older people's fear of involvement with social workers perceived as both devaluing of same sex relationships and insensitive to heterosexist assumptions behind service provision that are reinforced by commonly used expressions such as 'marital status', 'next of kin' and 'family commitments'. This invisibility pushes older LGBT people to be 'out' to challenge such inappropriateness yet fears of stigmatization have also led to the assertion of the right not to be 'out' (Richardson, 2000, in ibid.). Charnley and Langley argue for a culturally competent social work

\footnotetext{
${ }^{1}$ Social policy in the different countries of the United Kingdom has diverged significantly since the creation of devolved parliaments and assemblies in Scotland, Wales and Northern Ireland.
} 
in the UK that requires practitioners to recognise the strengths of alternative family and community structures, with a commitment to support those structures in times of need. Personalisation policy emphasised an individualised 'outcomes'-focused approach to service provision, arguably providing opportunities for social workers to engage more creatively with LGB service users (Cocker \& HaffordLetchfield, 2010). The Care Act embeds and strengthens that framework.

This article will explore the discretionary space opened up by the Care Act in relation to the specific circumstances of LGBT older people, focusing primarily on the assessment of adults needing care and support and their carers (sections 9 and 10), whilst also considering sections of the act that address interventions for prevention (section 2 ) and the promotion of diversity in the provision of services (section 5). It will critically examine the legislation, its regulations and statutory guidance in light of published work on the needs and resources of older LGBT people ${ }^{2}$, including their social networks. Finally, the Care Act's guidance for assessment and eligibility will be employed to analyse a published case study of two older gay men (Cronin \& King, 2010), in order to illustrate how the provisions of the Act can be positively applied in light of findings in the wider literature.

\section{The Care Act 2014}

In England the primary legal responsibility for ensuring the organisation and provision of care and support services for adults lies with local councils ('local authorities'). Services are funded through a combination of taxation and individual co-payments and provided on the basis of an assessment of need by the local authority, usually undertaken by social workers or social work assistants. Provision is subject to a means test that determines how much the service user is required to contribute to the overall cost of their care. The Care Act merges and strengthens core elements of previous policies and Acts of Parliament into a single new statute. It aims to produce a person-centred system that acknowledges people's strengths and capabilities as well as their needs, and places the concept of 'individual wellbeing' at its heart, creating a general legal duty for local authorities to promote individual wellbeing in the exercise of its care and support functions. The legislation defines the following domains of wellbeing:

- Personal dignity;

- Physical and mental health and emotional wellbeing;

- Protection from abuse and neglect;

- Control by the individual over day-to-day life (including over the provision of care and support);

- Participation in work, education, training or recreation;

- Social and economic wellbeing;

- Domestic, family and personal;

- Suitability of living accommodation;

\footnotetext{
${ }^{2}$ The uneven coverage in the literature of the component LGB and, especially, T communities of older people will inevitably be reflected in this piece, including the availability of published case studies that could be used to explore the Care Act.
} 
- The individual's contribution to society.

The accompanying statutory guidance (Department of Health, 2014a) emphasises that each domain should be regarded as equally important when an individual's overall wellbeing is under consideration. These domains further interact with the outcomes set out in the Care Act's underpinning regulations (Department of Health, 2014b), which largely focus on daily living but importantly also address wider social factors, to create the first national minimum eligibility criteria for the provision of care and support.

Running throughout the legislation and its associated regulations and guidance is an emphasis on outcome focused, asset-based responses to support people in their own communities, rather than a deficit-based model that itemises what people are no longer able to do (TCSW, 2015). The language of the guidance in particular is broadly open and inclusive, providing an architecture through which the needs and strengths of individuals can be identified in the context of their particular networks of support. The focus on locality, however, may be problematic for older LGBT people, an issue explored in more detail below.

\section{Key principles}

A number of key principles are embedded in the Act, including the assumption that individuals are best placed to judge their own wellbeing; the need in a person-centred system to take into account the particular views, feelings or beliefs of an individual; the importance of prevention; the expectation that all of a person's circumstances will be taken into account; the requirement to see people not simply as individuals in need of care but to understand them in the context of their families and support networks; the need to protect people from abuse; and the principle of least restrictive course of action. Finally, local authorities must ensure their commissioning practices and the services delivered either directly or on their behalf comply with the requirements of the Equality Act 2010 and not discriminate against people with protected characteristics, including age, gender reassignment, sex, and sexuality (Department of Health, 2014a).

\section{An emerging population}

The emergence of populations of older people who self-identify as LGBT is a historically new phenomenon. However these groups do not constitute fixed, catch-all sexual categories with an associated set of characteristics and social welfare needs (Cronin, Ward, Pugh, King, \& Price, 2011; Hicks, 2008). There are cohorts whose different life experiences pre- and post-'gay liberation' will have shaped and continue to shape their lives and relationships (Ramirez-Valles, Dirkes, \& Barrett, 2014; Rosenfeld, 2003), and those who, adopting a non-heterosexual identity later in life, may have a more problematic relationship with existing LGBT networks (Cronin \& King, 2014). LGBT identities differentiate in other ways too, with regards to intersections of 'race' or class (Purdie-Vaughns \& Eibach, 2008), even though a shared history of discrimination may simultaneously mitigate more obvious social divisions (Coon, 2003). The concept of 'heteronormativity' can assist with understanding that discrimination, defined as the belief that sex, gender and sexuality are inextricably linked and that heterosexuality is normal, natural and the pivot around which society is organised, including traditional understandings about how men and women should behave, e.g. gender roles, family relationships, etc. (Cronin \& King, 2010, 2014). Cronin and King argue that 
health and social care policy and practice is significantly framed by both heteronormative and ageist attitudes.

\section{The needs of older LGBT people}

It has been argued that sexual orientation accounts for little variation regarding the basic physiological needs of nutrition, hydration, medication or toileting (Pugh, 2012). However, there are likely to be specific needs for both older trans people and ageing gay men with HIV (Bailey, 2012; Wright, Owen, \& Catalan, 2012). Indeed, Caring and Aging with Pride, a national study in the USA, found that lesbian, gay, and bisexual older adults have higher rates of poor mental health and disability than their older heterosexual peers, with a higher risk of cardiovascular disease and obesity among older lesbians and bisexual women than for older heterosexual women. Older gay and bisexual men are also more likely than heterosexual men of similar age to have poor general health and to live alone (Fredriksen-Goldsen, Hoy-Ellis, Goldsen, Emlet, \& Hooyman, 2014). A recurrent theme in the international literature has been identified that indicates the health, social care and housing needs of LGBT older people are primarily influenced by a number of forms of discrimination that impact upon the provision of, access to and take up of services (Addis, Davies, Greene, MacBride-Stewart, \& Shepherd, 2009). Addis et al. found reluctance amongst many LGBT people to disclose their identities to health professionals that arose from the anticipation of negative responses, with some instead providing clues that only those health and social care providers attuned to the experiences of under-represented groups might pick up. They note the widespread failure of agencies to acknowledge the needs of these groups as users of health, mental health and social care services and found limited understanding of any specific health, social care and housing needs of LGBT older people, highlighting a scarcity of research in this area. Existing research is criticised for using small samples and for tending to exclude participants from less affluent and/or minority ethnic backgrounds, with a focus on gay men and lesbians, the needs of bisexual and transgender people remaining largely unknown, and a bias towards a narrow range of health issues of relevance primarily to younger LGBT people.

Bailey (2012) describes two distinct groups amongst a new wave of older trans individuals: those who transitioned years ago and have aged in their chosen sex; and those who transition in later life, often to avoid negative personal or social consequences. Both groups face distinctive health issues that may impact on their care and support. The former may experience unforeseen consequences of lifelong hormone therapy and/or having experienced surgical procedures that were in development at the time of their transition, and the latter potential restrictions to their transition options given the greater health risks associated with both hormone and surgical treatments for older people. In particular there are real fears that the potential exposure of complex bodies, which may reveal discrepancies between someone's gender and their birth sex in the course of health or social care interventions, could lead to negative reactions from staff. In addition, trans people may not be in touch with their families of origin, seeking instead to form alternative families and support systems that need to be recognised. Indeed, transgender older adults experience the highest rates of victimization as compared to non-transgender lesbian, gay, and bisexual adults, and have even higher rates of disability, stress, and poor mental and physical health (Fredriksen-Goldsen, CookDaniels, et al., 2014). 
Gay men ageing with HIV must contend with the complexity of co-morbidities and co-infection, alongside the 'double jeopardy' of ageism and HIV stigma that can lead to discrimination, stereotyping, rejection and social isolation, alongside a continuing emotional burden and damaged social networks as a consequence of AIDS-related bereavements amongst long-term survivors (Wright et al., 2012). Stonewall's (2012) survey found that LGB individuals over 55 are significantly more likely to be single and live alone, less likely to have children or be in regular contact with their family of origin, with the majority not confident that social care services would understand and meet their future needs as LGBT older people, fearing prejudicial attitudes or discrimination. Indeed, the former Commission for Social Care Inspection's (2008) survey found that 45 percent of LGBT respondents reported discrimination.

Several themes of particular relevance to the Care Act emerge from this brief overview, specifically the importance of social networks (as well as the damage to them that can result from experiences of homophobia, transphobia and the AIDS epidemic), unacknowledged differences in health and care needs, and the persistent fear that services will respond, if at all, negatively to these emerging groups of older LGBT people.

\section{Social Networks and the Care Act}

The statutory guidance routinely uses 'family or friends', 'family or other support network', rather than 'family' alone in a manner that indicates at least some awareness of the different ways adults' networks may be constructed. The core principles can be interpreted in an LGBT positive way, central amongst them the requirement to see people not simply as individuals in need of care but to understand them in the context of their families and support networks. This fits with research that identifies links between the general wellbeing of older people, the patterns of their social networks and the propensity to need formal care and support (Wenger, 1997). With a normative focus on families of origin and locality, however, the framework for this research may be problematic if applied to older LGBT people. 'Locality' in particular reflects two further aspects of the Care Act that may be especially problematic in relation to older LGBT people and their networks, firstly, that both eligibility and service provision are dependent on 'ordinary residence' (the requirement to reside within the boundaries of the local authority), and secondly, the emphasis on community and locality that runs throughout the Act and its guidance.

\section{Older LGBT people and their support networks}

Heaphy (2009) cautions that the 'families of choice' thesis, which conceptualises lesbian and gay relational formations as 'chosen' families that may include partners, children (where they exist), expartners, friends and accepting members of families of origin, can downplay significant differences among lesbians and gay men, particularly serving to overlook the experiences of the less privileged. He found mixed evidence for the concept, with respondents in his UK study rating relationships with family of origin as important but many reporting distance as a consequence of their sexuality too. The vast majority considered friendship to be important, with most reporting it as more important with increasing age, although partners and/or professionals were the preferred options for the potential provision of care, reflecting Shippy, Cantor and Brennan's (2004) findings amongst older gay men in New York (two thirds of whom lived alone). The issue of future care provision presented considerable anxiety for the similarly high proportions of Heaphy's (2009) respondents without partners and living alone. Only just over a third of respondents lived close to a relative, with few 
expecting them to provide care and support. For most, however, the idea that friends could provide this went beyond the bounds of expectation in friendship relationships, an important question that requires further research.

Grossman, D'Augelli and Hershberger (2000) identified an average network size of six people in their sample of LGB older people in the USA, most of whom were classified as close friends. Two thirds of these network members were themselves LGB, however, the sexuality of network members did not affect the older person's satisfaction with the support received. Much more significant was whether the network member was fully aware of the older person's LGB identity. Indeed this one factor was identified as the single most important predictor of satisfaction with support received from any network member, regardless of sexuality, an important finding with implications for service provision. Grossman et al note how, historically, older LGB adults have had to create support networks for themselves, with the presence of high proportions of LGB network members perhaps reflecting participants' concern for safety and security from an earlier life stage. They also show how those who live with partners enjoy greater and more satisfying networks, highlighting the wider risks to wellbeing that can arise when a partner dies.

The Care Act's core principle that adults should be seen in the context of their families and support networks facilitates engagement with such complexity of relational life, whether in the course of assessing the need for care and support, identifying and supporting carers or commissioning appropriate services in the community. As noted, however, the assumption of 'locality' in notions of community is problematic, deriving from the idea of 'communities of place' (Cronin et al., 2011).. Drawing on studies of ethnic minority communities Cronin and King (2014) show how networks of trust and reciprocity develop on the basis of shared identity and interest, not necessarily shared locality. They identify evidence of geographically-dispersed lesbian and gay social networks successfully using online resources to support personal and political networking outside of the more visible 'gay enclaves', suggesting that 'communities of place' may not be a primary focus in the lives of many older LGBT people. Indeed, Cronin et al. (2011) highlight how 'communities of place' may instead be experienced as perceived or actual sources of threat that influence whether LGBT people are 'out' in their dealings with their neighbours. This may lead to the community with whom they identify not being the community of place at all but rather a dispersed LGBT community, a factor that could raise questions of eligibility in relation to the Care Act, particularly where older LGBT people want to access services that lie outside of their own local authority boundaries.

\section{Implications for commissioning and prevention}

This presents challenges for commissioning managers that may necessitate collaboration between local authorities as outlined in Section 5 of the Care Act. The guidance makes it clear commissioners should engage with stakeholders to better understand supply and demand and articulate likely trends in people's evolving needs to help develop the wider social care market. As noted, local authorities must ensure their commissioning practices and the services delivered on their behalf comply with the requirements of the Equality Act 2010 not to discriminate against people with protected characteristics, and specifically that local authorities should review care and support services for their appropriateness for people from different communities, cultures and beliefs. Under Section 2 of the Act a local authority must provide services, facilities or resources to contribute towards preventing, reducing or delaying the development by adults or carers of needs for care and 
support. In doing so, it must "have regard to" the importance of identifying adults and carers with needs for care and support that are not being met. The guidance outlines various ways a local authority can address its responsibilities to prevent, reduce or delay the need for care and support. For example, with regards to primary prevention (aimed at adults with no current health or support needs) community-based activity or befriending services are highlighted as particularly effective in reducing social isolation. The guidance explicitly requires local authorities to consider how they can work with different partners, including voluntary sector organisations, to identify unmet needs for different groups (Section 2.31). Given the prevalence of older LGBT people living alone (Heaphy, 2009; Shippy et al., 2004; Stonewall, 2012) there is a clear lever here for the development and joint commissioning of prevention services targeted at older LGBT people in collaboration with local LGBT groups.

\section{Assessment}

An assessment under the Care Act must identify the person's needs, how those needs constrain their ability to achieve any outcomes they wish to achieve and the consequent effects on their wellbeing. The interrelationship between these three factors, needs, impact on desired outcomes and consequences for wellbeing, is critical to determining eligibility, i.e. whether the local authority must meet those needs. Local authorities must consider the person's own strengths and capabilities, and any support available from their wider network or within the community that might contribute towards achieving their desired outcomes. Where an individual provides or intends to provide care for another adult and it appears that the carer may have any level of need for support, local authorities must also carry out a carer's assessment. The 'whole family approach' (sic) requires local authorities to identify how the adult's needs for care and support impact on family members or others in their support network.

The Care and Support (Eligibility) Regulations Sections 2 (1) and 2 (2) set out the new national minimum eligibility criteria as follows:

An adult's needs meet the eligibility criteria if:

a) the adult's needs arise from or are related to a physical or mental impairment or illness;

b) as a result of the adult's needs the adult is unable to achieve two or more of the outcomes specified [in the regulations]; and

c) as a consequence there is, or is likely to be, a significant impact on the adult's well-being

The regulations further define what 'being unable' might mean in relation to with or without assistance, causing pain or risk, and include guidance on how fluctuating needs are to be taken into account.

\section{Case Study}

Cronin and King (2010) explore the complex interdependencies of Alec (64) and Peter (55). Friends for over twenty-five years they live together but are not a couple in the traditional sense. Their relationship could be construed as a 'family of choice', their lives being very much intertwined. Their case study will be re-presented here to illustrate how the provisions of the new Care Act can be applied to real life circumstances, in this instance those of two older gay men. Superficially it looks as though Peter, a nurse, has 'cared for' Alec, a diabetic. When they met Alec was experiencing 
difficulties with his diabetes and Peter took charge, ensuring Alec saw specialists and received more appropriate care, nursing him when he was especially ill and helping him to cope. Alec later retired on health grounds, with Peter continuing to support him financially. This surface picture is, however, misleading. They met through a gay support group, when Peter was struggling to accept his sexuality in the face of distressing family hostility. Alec played a significant role in enabling Peter to accept his sexuality. In this sense, Alec 'cared for' Peter psychologically and this dynamic underpins their relationship. Their care practices are embedded in their identities as gay men, caring for each other partly because their sexuality brought them together but also as a consequence of how their choices have been (and continue to be) shaped by the heteronormative society in which they grew up and are growing older. They are not a 'couple' in a traditional sense, yet their relationship is a central fact of their lives. Hicks (2008) alerts us to the danger that particular 'versions' of LGBT lives may be 'approved' by social workers, with the risk that non-approved versions are not taken as seriously.

Alec has suffered further ill health and Peter, though still in work, has also had periods of illness. Cronin and King present the continuing complex set of practices relating to support, care and interdependence that this pair of friends enact, with Peter learning to cope with Alec's increasing infirmity, and Alec facing Peter's growing depressions and frustrations. Both fear for the future, Alec fearing Peter will grow tired of caring for him and leave, and Peter concerned he will not be able to cope with Alec's needs as he ages himself. Any social worker arriving to undertake an assessment would not necessarily know, however, that Alec and Peter are gay and may need to be sensitive to clues in the environment or in their narratives (Cronin et al., 2011), whilst avoiding unwarranted assumptions based on fixed notions of what being gay might mean.. They very clearly sit within a 'young-old' cohort (Rosenfeld, 2003) of gay men, whose lives may well have been shaped by the ideas and practices of 'gay liberation' (support groups, LGBT community resources, 'coming out' etc.), but also to have been affected either directly or indirectly by the AIDS epidemic (RamirezValles et al., 2014) and, in the UK, to have experience of unequal ages of consent and police harassment under previous governments. Although likely to be 'out' in their dealings with the world, they may nonetheless be circumspect with any social services staff coming into their home.

In relation to the Care Act Alec's increasing ill health would likely be the trigger for an assessment. However, even if he refused an assessment Peter could request one in his own right but in the role of 'carer', the Act's provisions forcing a role dichotomy that is less complex than their lived experience. If Alec agreed to an assessment they could (and should) be assessed together, although there is also provision in the Act for joint assessments with the NHS to be undertaken so other options might include a combined health and social care assessment for Alec with a community based nurse. Alec's needs very clearly arise from a physical illness, so the key question is whether those needs make him 'unable' (within the definitions of the Act) to meet at least two of the outcomes specified in the regulations (Department of Health, 2014b) and whether this inability then impacts significantly on his wellbeing. It is very possible that, given Alec's ill health, many of the outcomes relating to managing his physical care could be compromised. However, even were this not the case, his increasing needs could still threaten his ability to develop and maintain family or other personal relationships (Section $2\{2\} \mathrm{g}$ ), as well as his ability to make use of necessary facilities or services in the local community including public transport and recreational facilities or services (Section 2\{2\}i). The inability to achieve both of these outcomes would be sufficient to meet the eligibility criteria, as long as this inability then has a significant impact on his wellbeing. Specific 
domains of Alec's wellbeing that are likely to be affected by the failure to achieve these outcomes could include:

- Physical and mental health and emotional wellbeing;

- Social and economic wellbeing;

- Domestic, family and personal;

As a carer Peter might also find he is unable to access and engage in work, training, education or volunteering (Section $2\{2\} \mathrm{h}$ ), due to increasing stress and his own illness threatening his employment, as well as being unable to maintain family or other personal relationships as the relationship with Alec comes under strain. All of this would impact on Peter's wellbeing in the same domains, with the addition of a further dimension, the individual's contribution to society. It is important to note that, even if their needs fail to meet the eligibility criteria, the local authority retains the duty to prevent, reduce or delay needs for care and support so would need to advise Alec and Peter accordingly.

The case study gives us few details about Peter and Alec's wider networks, other than noting they both have previous long term partners, so their wider contacts and connections, whether family of choice or origin, would need to be mapped to see what resources might exist to support them. For example, Peter's relationship with his family could just as easily have improved as deteriorated over the years. The assessment must also include consideration of their individual strengths. Alec's history of support for Peter might signal potential for contributing to mutual support networks, perhaps an expert patient programme for diabetics. Peter in turn might benefit from targeted preventive services for LGBT carers to enable him to maintain his employment and his own independent life whilst still providing care and support for Alec. Should they in fact need formal care and support services, they could shape this themselves using either direct payments or an individual budget, the amount of which would depend on their financial assessment. Indeed, a further new provision in the act allows individuals to pool their budgets with others, a mechanism that has existed for some years in German care legislation ( $\$ 36$ SGB XI) and underpinned the recent development of a shared living facility for older gay men with high care needs in an internationally acclaimed housing project in Berlin (www.schwulenberatungberlin.de/projekte/lebensort-vielfalt, personal communication). This mechanism opens up entirely new possibilities for community development.

\section{Conclusion}

This article has drawn on a range of conceptual and research literature to critically engage with key provisions of the Care Act in England and suggests how those provisions might be interpreted and applied in ways that fully recognise and support older LGBT individuals and their needs in the context of their wider social networks. It takes the view that legislation, regulations and guidance create spaces for professional discretion and highlights areas where that discretion could be utilised in a positive manner. It has identified three key strands-firstly, the need to understand older LGBT people and their networks in the context of their experiences of hostility and discrimination. In a period of improving legal rights it is easy to forget how recent such changes are and that the reluctance amongst many older LGBT people to identify themselves to service providers arises from 
justified fears. This requires both sensitivity and sophistication in approaches to practice and above all a willingness to actually recognise the existence of this group. Secondly, older LGBT social networks need to be better understood (in both research and practice), particularly with regards to how such networks can be explicitly supported and developed using the provisions of the Care Act. Thirdly is the related tension between the locality focus of the legislation, including the impact of 'ordinary residence', and the assumptions about 'communities of place' that raises complications at both individual and collective levels for more dispersed communities. Commissioning managers in particular may need to review how their commissioning practices enable or constrain the development of appropriate services for older LGBT people in light of their equality duties, whilst social workers and other assessment staff have an opportunity to act as change agents in a heteronormative care system and make a significant contribution to improved wellbeing amongst older LGBT people in their communities. 


\section{References}

Addis, S., Davies, M., Greene, G., MacBride-Stewart, S., \& Shepherd, M. (2009). The health, social care and housing needs of lesbian, gay, bisexual and transgender older people: a review of the literature. Health \& Social Care in the Community, 17(6), 647-658. doi: 10.1111/j.13652524.2009.00866.x

Bailey, L. (2012). Trans ageing: thoughts on a life course approach in order to better understand trans lives. In R. Ward, I. Rivers \& M. Sutherland (Eds.), Lesbian, gay, bisexual and transgender ageing: biographical approaches for inclusive care and support (pp. 51-66). London: Jessica Kingsley.

Brammer, A. (2010). Social Work Law. Harlow: Pearson Education Ltd.

Braye, S., \& Preston-Shoot, M. (2010). Practising social work law. Basingstoke: Palgrave Macmillan. Charnley, H. M., \& Langley, J. (2007). Developing cultural competence as a framework for antiheterosexist social work practice: reflections from the UK. Journal of social work, 7(3), 307321.

Cocker, C., \& Hafford-Letchfield, T. (2010). Out and proud? Social work's relationship with lesbian and gay equality. British Journal of Social Work, 40(6), 1996-2008.

Commisison for Social Care Inspection. (2008). Putting people first: equality and diversity matters 1 : providing appropriate services for lesbian, gay, bisexual and transgender people. London: Commission for Social Care Inspection.

Coon, D. W. (2003). Lesbian, gay, bisexual and transgender (LGBT) issues and family caregiving. San Francisco, CA: Family Caregiver Alliance.

Cronin, A., \& King, A. (2010). A queer kind of care: some preliminary notes and observations. In R. Jones \& R. Ward (Eds.), LGBT issues: looking beyond categories (pp. 69-81). Edinburgh: Dunedin.

Cronin, A., \& King, A. (2014). Only connect? Older lesbian, gay and bisexual (LGB) adults and social capital. Ageing \& Society, 34(02), 258-279. doi: doi:10.1017/S0144686X12000955

Cronin, A., Ward, R., Pugh, S., King, A., \& Price, E. (2011). Categories and their consequences: Understanding and supporting the caring relationships of older lesbian, gay and bisexual people. International Social Work, 54(3), 421.

Department of Health. (2007). Putting People First: London, TSO.

Department of Health. (2014a). Care and support statutory guidance: Issued under the Care Act 2014. London: Department of Health Retrieved from https://www.gov.uk/government/uploads/system/uploads/attachment data/file/366104/4 338023902777 Care Act Book.pdf, accessed 15.05.2015.

Department of Health. (2014b). Secondary legislation: draft regulations for consultation--part 1 of the Care Act 2014. London: Department of Health Retrieved from https://www.gov.uk/government/uploads/system/uploads/attachment data/file/315215/d raft regs.pdf, accessed 22.05.2015.

Evans, T., \& Harris, J. (2004). Street-level bureaucracy, social work and the (exaggerated) death of discretion. British Journal of Social Work, 34(6), 871-895.

Fredriksen-Goldsen, K. I., Cook-Daniels, L., Kim, H.-J., Erosheva, E. A., Emlet, C. A., Hoy-Ellis, C. P., . . . Muraco, A. (2014). Physical and mental health of transgender older adults: An at-risk and underserved population. The Gerontologist, 54(3), 488-500.

Fredriksen-Goldsen, K. I., Hoy-Ellis, C. P., Goldsen, J., Emlet, C. A., \& Hooyman, N. R. (2014). Creating a Vision for the Future: Key Competencies and Strategies for Culturally Competent Practice With Lesbian, Gay, Bisexual, and Transgender (LGBT) Older Adults in the Health and Human Services. Journal of Gerontological Social Work, 57(2-4), 80.

Grossman, A. H., D'Augelli, A. R., \& Hershberger, S. L. (2000). Social Support Networks of Lesbian, Gay, and Bisexual Adults 60 Years of Age and Older. The Journals of Gerontology Series B: Psychological Sciences and Social Sciences, 55(3), P171-P179. doi: 10.1093/geronb/55.3.P171 
Health and Care Professions Council. (2012). Social workers in England: standards of proficiency Sections 5 and 6. London: Health and Care Professions Council.

Heaphy, B. (2009). Choice and its limits in older lesbian and gay narratives of relational life. Journal of GLBT Family Studies, 5(1/2), 119.

Hicks, S. (2008). Thinking through sexuality. Journal of social work, 8(1), 65-82.

Howe, D. (1991). Knowledge, power and the shape of social work practice. In M. Davies (Ed.), The sociology of social work. London: Routledge.

Lipsky, M. (1980). Street Level Bureaucracy: Dilemmas of the Individual in Public Service. London: Sage.

Pugh, S. (2012). Care anticipated: older lesbians and gay men consider their future needs. In R. Ward, I. Rivers \& M. Sutherland (Eds.), Lesbian, gay, bisexual and transgender ageing: biographical approaches for inclusive care and support (pp. 39-50). London: Jessica Kingsley.

Purdie-Vaughns, V., \& Eibach, R. P. (2008). Intersectional invisibility: The distinctive advantages and disadvantages of multiple subordinate-group identities. Sex Roles, 59(5-6), 377-391.

Ramirez-Valles, J., Dirkes, J., \& Barrett, H. A. (2014). GayBy Boomers' social support: Exploring the connection between health and emotional and instrumental support in older gay men. Journal of Gerontological Social Work, 57(2-4), 218-234.

Rosenfeld, D. (2003). The changing of the guard: Lesbian and gay elders, identity, and social change. Philadelphia: Temple University Press.

Shippy, R. A., Cantor, M. H., \& Brennan, M. (2004). Social Networks of Aging Gay Men. Journal of Men's Studies, 13(1), 107-120.

Stonewall. (2012). Lesbian, gay and bisexual people in later life. London: Stonewall.

TCSW. (2015). Additional statements for social workers working with the Care Act. London: The College of Social Work.

Wenger, G. C. (1997). Social networks and the prediction of elderly people at risk. Aging \& Mental Health, 1(4), 311-320.

Wright, R., Owen, G., \& Catalan, J. (2012). 'I'm older than I ever thought I would be': the lived experience of ageing in HIV-positive gay men. In R. Ward, I. Rivers \& M. Sutherland (Eds.), Lesbian, gay, bisexual and transgender ageing: biographical approaches for inclusive care and support (pp. 85-101). London: Jessica Kingsley. 